\title{
Entre o social e a técnica: os processos midiatizados do fenômeno religioso contemporâneo ${ }^{1}$
}

\author{
Moisés SBARDELOTTO ${ }^{2}$
}

\begin{abstract}
RESUMO
Em um processo de midiatização do fenômeno religioso, passam a surgir novas modalidades de experienciação da fé, a partir do deslocamento de práticas religiosas para a ambiência comunicacional da internet. Este artigo visa a analisar o conceito de midiatização em suas processualidades na interface com o fenômeno religioso no âmbito das redes. Examina-se também o papel da técnica nas interações comunicacionais, como base para a relação e a interação especificamente midiatizada entre fiel e sagrado, a partir de inovações tecnológicas e invenções sociais. Por fim, apontam-se alguns elementos de conclusão para compreender a midiatização como processualidade sociotécnica que marca as sociedades contemporâneas, incluindo seus fluxos religiosos.
\end{abstract}

Palavras-chave: Midiatização; religião; técnica; cibercultura; pós-humano.

\begin{abstract}
In a process of mediatization of religious phenomenona, new ways of experiencing faith emerge, from the displacement of religious practices to the communicational ambiance of internet. This article aims to analyze the concept of mediatization in its processualities in the interface of religious phenomenona within the Web. It also examines the role of technic in communicational interactions, as the basis for the specifically mediatized relationship and interaction between faithful and the sacred, by technological inovations and social inventions. Finally, it points out some elements of conclusion to understand the mediatization as sociotechnical processuality that marks contemporary societies, including their religious fluxes.
\end{abstract}

Keywords: Mediatization; religion; technic; cyberculture; post-human.

\section{Introdução}

Existe hoje, por meio das tecnologias digitais, a configuração de um novo tipo de interação comunicacional-religiosa. Com o surgimento de uma nova ambiência social, impulsionada pelo desenvolvimento de novas possibilidades comunicacionais on-line,

\footnotetext{
${ }^{1}$ Trabalho apresentado à terceira edição da Revista Ação Midiática - Estudos em Comunicação, Sociedade e Cultura, publicação ligada ao Programa de Pós-Graduação em Comunicação e Sociedade, da Universidade Federal do Paraná.

${ }^{2}$ Mestre e doutorando em Ciências da Comunicação pela Universidade do Vale do Rio dos Sinos (Unisinos), São Leopoldo/RS. Bolsista do CNPq. Possui graduação em Comunicação Social - Jornalismo pela Universidade Federal do Rio Grande do Sul (UFRGS). Ex-coordenador do Escritório da Weltethos Stiftung no Brasil. É colaborador do Instituto Humanitas Unisinos (IHU). E-mail: msbardelotto@yahoo.com.br.
} 
estabelece-se uma interação entre o fiel - por meio da internet - e elementos de sagrado, aqui entendido como aquilo que se costuma chamar de Deus, o "Totalmente Outro" (BOFF, 2002), o "superior summo meo" (superior a tudo, sempre maior) (BOFF, 2002), o "numinoso" (do latim numen $=$ divindade $)($ MARTELLI, 1995).

Isso possibilita uma experiência espiritual-religiosa por meio da rede, isto é, "uma relação interior com a realidade transcendente" (MARTELLI, 1995, p. 135). As pessoas passam a encontrar uma oferta da fé não apenas nas igrejas de pedra, nos sacerdotes de carne e osso e nos rituais palpáveis, mas também na religiosidade existente e disponível nos bits e pixels da internet. Assim, o fiel, onde quer que esteja, quando quer que seja - diante de um aparelho conectado à internet -, desenvolve um novo vínculo com o transcendente e um novo ambiente de culto.

Esse fenômeno é ilustrado, na prática, pela existência, no ambiente católico, de inúmeros serviços religiosos on-line que oferecem possibilidades para a prática religiosa fora do âmbito tradicional do templo: versões on-line da Bíblia e de orações católicas; orientações via internet com líderes religiosos; pedidos de oração on-line; as chamadas "velas virtuais"; programas de áudio e vídeo, como missas, palestras e orientações; "capelas virtuais", dentre muitas outras opções. Ou seja, aquilo que chamamos de rituais on-line, em que o fiel experiencia a sua fé e interage, por meio do sistema católico on-line, com Deus.

Analisamos alguns desses elementos em nossa pesquisa anterior (cf. SBARDELOTTO, 2012a; 2012b; 2011), em que buscamos compreender as interações comunicacionais desenvolvidas nas práticas religiosas on-line. Naquele contexto, buscávamos compreender como se davam as interações entre fiel-sagrado para a vivência, a prática e a experienciação da fé nos rituais on-line do ambiente digital católico brasileiro. Assim, examinamos as estratégias desenvolvidas para a oferta do sagrado, por parte do sistema católico on-line (o complexo de elementos comunicacionais em interação nos sites católicos), e as estratégias de apropriação desenvolvidas pelo fiel, por meio dos níveis tecnológico e simbólico da interface interacional; dos fluxos de interações discursivas; e dos fluxos de interações rituais no corpus de sites católicos analisados.

Essas novas práticas religiosas apontam para o processo de midiatização das sociedades contemporâneas. Ou seja, passam a surgir novas modalidades de experienciação da fé, embebidas em lógicas midiáticas a partir do deslocamento das práticas religiosas para a ambiência comunicacional da internet. E a interação midiatizada entre o fiel e o sagrado 
confere um papel central à técnica e às tecnologias comunicacionais, em uma complexa apropriação por parte da sociedade.

Este artigo, portanto, a partir de uma análise bibliográfica, visa a analisar o conceito de midiatização em seus tensionamentos com o fenômeno religioso no âmbito das redes. Examina-se também o papel da técnica nas interações comunicacionais, que permite, de forma mais específica, a relação e a interação midiatizadas entre o fiel e o sagrado. Por fim, apontam-se alguns elementos de conclusão para compreender a midiatização como processualidade socio-técnico-simbólica que marca as sociedades contemporâneas, incluindo também seus fluxos religiosos.

\section{Midiatização da religião: processo sociotécnico de construção de sentido}

$\mathrm{Na}$ interação estabelecida pelo fiel, por meio da internet, com elementos do sagrado, percebemos elementos que indicam as possibilidades de ocorrência de uma experiência espiritual-religiosa por meio da rede. Abrange-se, assim, um processo que se encontra em uma interface do sistema comunicacional com um amplo âmbito social, o religioso, interface que se dá em um movimento criativo e contínuo: ou seja, um processo midiático e social complexo. Ou seja, uma processualidade que aponta para a midiatização das sociedades contemporâneas.

Entendemos por midiatização um fenômeno, uma processualidade e um conceito em andamento, não finalizados e em debate. Em termos gerais, a midiatização pode ser entendida como um metaprocesso, segundo Krotz (2007). Para o autor, metaprocessos são "construtos que descrevem e explicam teoricamente dimensões e níveis econômicos, sociais e culturais específicos de mudança real" (KROTZ, 2007, p. 257, tradução nossa). Exemplos históricos desses metaprocessos são a racionalização, a urbanização, a mercantilização, a individualização, a secularização, a globalização, processos que duram por séculos e que não estão necessariamente confinados a determinada área ou cultura, nem se sabe exatamente quando começam ou terminam. A midiatização, portanto, pode ser entendida como um metaprocesso comunicacional que nos ajuda a entender a sociedade contemporânea, a partir da transformação social que se desencadeia por meio de processos midiáticos, como veremos.

É esse metaprocesso, dentre os demais, que molda as condições de vida social a longo prazo, tanto em nível micro (as ações e os processos de produção de sentido), quanto em nível médio (as atividades das instituições e organizações sociais), e ainda em nível macro (a 
natureza de uma determinada cultura e sociedade) (cf. KROTZ, 2007). A midiatização pode ser entendida como um metaprocesso, nesse contexto, porque se baseia na "modificação da comunicação como a prática básica da forma como as pessoas constroem o mundo social e cultural" (KROTZ, 2007, p. 25, tradução nossa).

Portanto, as "práticas comunicacionais" que estão na base da sociedade hoje estão em íntima ligação com as mídias. Hoje, as mídias são "marca, modelo, matriz, racionalidade produtora e organizadora de sentido" (MATA, 1999, p. 84, tradução nossa). Mas, na perspectiva da midiatização, as mídias não são entendidas apenas como os suportes tecnológicos da comunicação - aparelhos eletrônicos, em suma. Aqui, entendemos as mídias como "dispositivos sociotécnicos e sociossimbólicos, baseados cada vez mais no conjunto de técnicas (e não mais em uma única técnica, como antigamente)" (MIÈGE, 2009, p. 110). Ou seja, são dispositivos técnicos para a produção de sentido que ganham significado comunicacional em sua relação com os usos e as práticas sociais.

Esses dispositivos midiáticos incluem elementos materiais, técnicos, empresariais, mercadológicos, organizacionais, conteudísticos etc. inter-relacionados, mas, como dissemos, não existem independentemente e não ganham sentido isolados das práticas sociais. A midiatização, dessa forma, para além do mero aspecto tecnológico ou do mero aspecto sociocultural, desdobra-se em dois processos sinérgicos: o processo tecnológico, que "corresponde à disponibilização de ações comunicativas midiatizadas para largas parcelas da população, dosando e redirecionando a comunicação massiva"; e o processo social, que "diz respeito a uma entrada experimental de participantes sociais nas práticas e processos antes restritos à indústria cultural” (BRAGA, 2012, p. 34). Assim, analisar a midiatização é analisar processos sociotécnicos em que a sociedade, para existir e se manter, produz a técnica comunicacional, que, por sua vez, lança a sociedade para novos patamares de conhecimento e de experiência do mundo, que, novamente, gera um aprimoramento ou o surgimento de novas técnicas, e assim sucessivamente, por meio das práticas sociais. As ações desses processos “não se restringem ao objeto 'meios' nem ao objeto 'receptores e suas mediações', mas os incluem, a ambos, em formações muitíssimo diversificadas e ainda articulados a outras formações" (BRAGA, 2012, p. 35), mediante invenções sociais sobre inovações tecnológicas que (re)direcionam os processos sociocomunicacionais.

Por isso, as mídias são justamente as interfaces, as conexões e as interconexões sociotécnicas que passam a estabelecer redes complexas de circulação comunicacional, não possíveis mais de serem fragmentadas em produtor, produção, conteúdo, veículo, público, 
receptor, recepção (cf. GOMES, 2010). Nesse contexto, a midiatização pode ser entendida como uma "ação das mídias", pois estas - principalmente a digital, em nosso caso - são um "lócus privilegiado para compreender a sociedade em seus diversos ângulos, bem como os processos que a animam e a estruturam. [...] A forma como o sistema midiático se estabelece, com seus processos estruturantes e seus modos de produção, fornece [...] os elementos essenciais para interpretar os inter-relacionamentos sociais e humanos hoje" (GOMES, 2010, p. 104).

Portanto, a midiatização aponta, nesse sentido, para um metaprocesso comunicacional que não apenas redefine, mas faz existir e permite a existência do que chamamos de cultura ou sociedade. Mais do que "mediações culturais da comunicação", há também “mediações comunicativas da cultura" (cf. BRAGA, 2012). Explicita-se, assim, a centralidade que a comunicação midiática foi adquirindo para o desdobramento dos fenômenos sociais e culturais contemporâneos - nesse sentido, a perspectiva da midiatização também permite um ponto de vista ecológico e ecossistêmico sobre os processos sociomidiáticos.

Além disso, em sociedades em midiatização, os fenômenos sociais, cada vez mais, passam a ser perpassados por processos midiáticos. Podemos entender esses processos como "o conjunto de práticas comunicacionais pertencentes ao sistema de meios que opera segundo diferentes linguagens através de [diversos] dispositivos" (GOMES, 2010, p. 104). Portanto, o "âmbito de feixes de relações [sociais, religiosas etc.] se estruturam cada vez mais em redes complexas de discursividades e de funcionamento dos signos" (FAUSTO NETO, 2009, p. 3). A midiatização, dessa forma, é um fenômeno que transcende e ultrapassa o campo midiático, inserindo-se em processualidades cujas dinâmicas ocorrem "a partir de suas próprias lógicas, operações, 'saberes' e estratégias na direção de outros campos sociais" (FAUSTO NETO, 2005, p. 10) - como, por exemplo, a religião. Assim, o "conteúdo" do fenômeno da midiatização são os processos midiáticos, cada vez mais abrangentes, cada vez mais acelerados, cada vez mais diversificados. Essa é "a chave hermenêutica de sua compreensão e interpretação" (GOMES, 2010, p. 104).

Em suma, ao abordarmos aqui a ideia de midiatização, estamos nos referindo a um fenômeno histórico manifestado por processos midiáticos desencadeados por práticas sociocomunicacionais de mediação cultural. Ou seja, é um fenômeno histórico porque é mais ou menos delimitável no tempo, manifestando-se a partir de determinadas condições históricas do desenvolvimento das sociedades. Essas condições históricas passam a permitir e a estimular a circulação de sentidos culturais diversos e difusos entre pessoas de um mesmo 
grupo ou campo social, ou entre grupos e campos sociais (mediação cultural). Assim, passam a surgir, dentre outras, práticas sociais especificamente voltadas à comunicação - ou seja, usos perduráveis que a sociedade vai dando às técnicas disponíveis. Essas técnicas vão ganhando novos sentidos, que levam ou ao seu aprimoramento ou ao surgimento de novas técnicas, que levam a novas práticas. Ao longo do tempo, portanto, diversos processos sociotécnicos específicos vão se conjugando - determinadas práticas/necessidades sociais, especificamente comunicacionais, levam ao surgimento de determinadas técnicas, que estimulam novas práticas/necessidades sociais (processos midiáticos) -, dando origem a esse metaprocesso histórico que chamamos de midiatização. Essa conceituação nos ajuda, também, a analisar a midiatização em perspectiva complexa, a partir dos três níveis propostos por Krotz (2007): em nível micro (práticas comunicacionais de mediação cultural), em nível médio (processos midiáticos) e ainda em nível macro (fenômeno histórico).

São essas lógicas, protocolos e processualidades sociotécnicos complexos que fundamentam e possibilitam um simples gesto do usuário como o de "acender uma vela virtual", por exemplo (cf. SBARDELOTTO, 2012a; 2012b; 2011). O gesto tradicional dispensava a "mídia" propriamente dita (embora fizesse uso de tecnologia: uma vela de cera e fogo). Aos poucos, porém, as práticas religiosas passam a ser midiatizadas, perpassadas por lógicas midiáticas. Assim, além de estar associada com as e ocorrer por meio das, a midiatização vai além das mídias, abrangendo processos tradicionais que ocorriam historicamente fora das mídias, midiatizando-os progressivamente.

Isso não significa que as mídias estejam substituindo ou eliminando as práticas religiosas ou a própria religião como a conhecemos tradicionalmente, nem que, somente graças às mídias, a religião continua mantendo seu espaço na vida social. A questão central é que esse novo gesto midiático do "acender velas virtuais" (dentre outros) só ganha sentido para o fiel porque a midiatização passa a ser um "princípio, um modelo e uma atividade de operação de inteligibilidade social" que gesta um novo "bios virtual", "um novo modo de ser no mundo", uma "nova ambiência" (GOMES, 2008, p. 20-21) para a construção de sentido social e também para a experiência religiosa. Como afirma Fausto Neto (2005, p. 3), "nada existiria fora, portanto, dessa nova conformidade [da midiatização], como possibilidade geradora de sentidos". Ou seja, os fenômenos sociais e religiosos passam a se constituir a partir de lógicas midiáticas, que se concretizam nas práticas sociais. A partir dessa compreensão, nasce uma ecologia ou ecossistema midiático, que constitui e mantém a 
interação e a comunicação humanas. Até mesmo a religião constrói e gera sentido ao fiel também por meio de processos sociais que ocorrem a partir do fenômeno da midiatização.

Assim, surge uma nova lógica sociocomunicacional e uma nova natureza sócio-organizacional. O âmbito da religião e de suas práticas também passa a se remodelar e a se reconstruir a partir das processualidades desse fenômeno - a midiatização da religião. Ou seja, a experiência religiosa também passa a ocorrer a partir das mídias, em uma relação sinérgica e em espiral entre processos sociais e processos tecnológicos, entre práticas sociocomunicacionais a partir de técnicas específicas, conceito que analisaremos agora.

\section{A técnica comunicacional e o pós-religioso}

O ser humano sempre buscou entender e explicar o mundo ao seu redor mediante técnica e tecnologias. A própria cultura é um fenômeno tecnológico desde as suas origens. Desde sempre, "as qualidades humanas se constroem na realização com o não-humano" (MARCHESINI, 2006, s/p), assim como as qualidades religiosas. Ainda em 1953, em sua mensagem de Natal, o Papa Pio XII, embora denunciando os riscos do "espírito técnico", afirmava: "A Igreja ama e favorece os progressos humanos. É inegável que o progresso técnico vem de Deus, e portanto pode e deve conduzir a Deus"”3.

Isso também foi reconhecido pelo Papa Bento XVI (2009, n. 69), em sua encíclica Caritas in Veritate. No documento, o pontífice afirma que "a técnica [...] é um dado profundamente humano, ligado à autonomia e à liberdade do homem. Nela exprime-se e confirma-se o domínio do espírito sobre a matéria". Na técnica, continua Bento XVI, "considerada como obra do gênio pessoal, o ser humano reconhece-se a si mesmo e realiza a própria humanidade". E acrescenta: a técnica "nunca é simplesmente técnica; mas manifesta $o$ ser humano e as suas aspirações ao desenvolvimento, exprime a tensão do ânimo humano para uma gradual superação de certos condicionamentos materiais" (grifo nosso). Nesse sentido, "a técnica é a essência do ser humano" (GOMES, 2010, p. 164). Mas o relevante é que, hoje, mais do que em qualquer outra época, com o avanço da midiatização digital ou hipermidiatização, técnica e tecnologia se tornaram um tema central de debate.

\footnotetext{
${ }^{3}$ A afirmação foi feita em sua radiomensagem de Natal, no dia 24 de dezembro de 1953, disponível em: $<$ http://migre.me/9a1gk $>$.
} 
Mas, afinal, o que é a técnica? No grego, techné está associado à episteme: ou seja, um saber (episteme) concretizado em práticas ou coisas (em um fazer). Assim, a técnica é a arte/capacidade de produzir, fabricar: um saber-fazer aplicado em tecnologias.

É preciso compreender que "se há ser humano é porque uma tecnologia o fez evoluir a partir do pré-humano" (SANTAELLA, 2010, p. 131), pois a nossa primeira técnica e a nossa primeira mídia, por consequência, foi a fala, tão natural quanto artificial. Por isso, é preciso reconhecer que o alfabeto e a escrita são tecnologias tanto quanto a roda, o telefone e o computador. "O homo sapiens é constitutivamente homo technologicus [...] por causa da própria constituição biológica" (PIREDDU, 2010, p. 47). Portanto, não há contraposição entre técnica e humano, técnica e natureza: ambos se retroinfluenciam. "A técnica não é só produção de manufaturados, mas também transformação daquele que os produz, é alteração, além da matéria e do ambiente, também do homem" (ESPOSITO, 2010, p. 246).

Mas aqui não nos interessamos por todas as técnicas. Falamos de técnicas e tecnologias comunicacionais, especialmente digitais. Assim, em perspectiva histórica, nas origens da comunicação digital, ainda na década de 1970, para compreender as primeiras inter-relações entre as então "novas técnicas" e o social surge o conceito de cibercultura. Esta seria uma cultura relacionada à "cibernética, à computadorização, à revolução digital, à ciborguização do corpo humano" (FELINTO, 2006, p. 95). De fato, a cibercultura deriva da cibernética, termo cunhado nas origens da informática, que deriva, por sua vez, do grego tekhné kybernetiké, a arte/técnica de pilotar, de governar embarcações. Ou seja, a cibernética seria a arte/técnica de "governar uma nave", de "pilotar máquinas", no auge da computadorização mundial.

O matemático norte-americano Norbert Wiener (1894-1964) foi um dos grandes pensadores da cibernética. Em plenas guerras mundiais, Wiener via nas máquinas comunicacionais uma forma de poder, de ordem e de organização que poderia afastar as sociedades em geral da entropia das forças de destruição. Dessa forma, um conceito-chave que embasa a ideia de cibercultura é informação. "Essa noção de código capaz de dar conta de toda realidade (dos sistemas informáticos aos sistemas vivos) constitui o centro da experiência cultural do mundo "ciber"” (FELINTO, 2007, p. 4). Portanto, a cibercultura seria a "expressão das formas de vida, práticas e problemas antropológicos ligados às tecnologias digitais" e "uma espécie de saber próprio do contemporâneo", na forma do "estudo de todos os fenômenos ligados à internet” (FELINTO, 2007, p. 5-6). Assim, a cibercultura se refere tanto à forma sociocultural que vai surgindo junto com as novas tecnologias da 
informação-comunicação como ao saber específico que se debruça sobre essa forma sociocultural.

Porém, hoje, não estamos diante apenas de um fenômeno decorrente dos aparatos tecnológicos ou das técnicas especificamente digitais, mas sim de um processo em que "os dispositivos tecnológicos são apenas uma mínima parcela, a ponta do iceberg, de um novo mundo, configurado pelo processo de midiatização da sociedade" (GOMES, 2010, p. 161). A "cibercultura", a nosso ver, por enfatizar apenas as tecnologias digitais, acaba deixando de perceber o fenômeno histórico que se desenvolve a partir das técnicas comunicacionais desde muito antes da computadorização - e, o mais importante, o que se desenvolve a partir das práticas sociais sobre essas técnicas. Por outro lado, às vezes, em certos estudos ciberculturais, há uma visão utópica e política da técnica como algo "melhor do que o humano", algo "para além do humano", "extra ao humano", que poderia ajudar na construção do "melhor dos mundos possíveis". Mas essa é uma visão muito restrita das técnicas e tecnologias, e de sua relação com o social.

Nesse sentido, retomando a etimologia da palavra (ciber), podemos questionar com Scolari (2008, p. 74, tradução nossa): tem "sentido definir em termos de controle um espaço que, se se caracteriza por algo, é pela polifonia de vozes e a falta de um centro de poder?”. Se seguimos o jogo dos profetas do ciberespaço, continua o autor, "esse já é um território liberado. Essa mesma objeção - referimos-nos ao uso do prefixo ciber - poderia ser aplicada ao conceito de ciberculturas". Segundo o autor, esse é um conceito que nunca deixou de se "desapegar totalmente da novela ciberpunk Neuromancer, de William Gibson, e do imaginário eletrônico-libertário" (SCOLARI, 2008, p. 75, tradução nossa).

Manovich (apud CABRAL, 2009, s/p) também segue a mesma linha:

Nos anos 90, só se falava de 'virtual', 'ciberespaço' e 'cibercultura'. Éramos fascinados pelas possibilidades que os espaços digitais ofereciam. $\mathrm{O}$ 'virtual', que existe à parte do 'real', dominou a década. Agora, a web é uma realidade para milhões, e a dose diária de 'ciberespaço' é tão grande na vida de uma pessoa que o termo não faz mais muito sentido. [...] O 'virtual' agora é doméstico. [...] Nossas vidas on-line e off-line são hoje a mesma coisa. Para os acadêmicos que ainda usam o termo 'cibercultura' para falar da atualidade, eu recomendo que acordem e olhem para o que existe em volta deles.

Precisamos reconhecer, naturalmente, que a contribuição das teorias da comunicação de massa, assim como da cibercultura, é importante, mas não suficiente. Hoje, é preciso "separar as águas de certa produção textual de caráter meramente especulativo ou diretamente extravagante" (SCOLARI, 2008, p. 143, tradução nossa). Muitas das contribuições dos 
estudos culturais sobre ciborgues e realidades virtuais ajudaram a oferecer novas perspectivas para a comunicação digital, mas, "pelo fato de estarem mais baseadas em especulações futuristas do que em estudos empíricos, contribuem pouco para o edifício teórico", aponta o autor. O mesmo acontece com os discursos utópicos e seus contrários distópicos. Em outras palavras, defende Scolari (2008, p. 144, tradução nossa), "o mosaico discursivo das ciberculturas é uma grande fonte para extrair novas perguntas e desafios, mas uma base frágil para construir uma reflexão teórica sobre as hipermediações”.

Por isso, ao contrário, "a difusão das tecnologias digitais da informação [...]," longe de ser o sintoma "de uma comunicação finalmente imaterial ou desencarnada", pode "ajudar-nos a descobrir a complexidade das relações vivas entre homem, tecnologia e ambiente" (PIREDDU, 2010, p. 53). No questionamento de que religião nasce da mídia, e do que a religião em midiatização revela acerca da mídia, estão em xeque os fundamentos de ambos os âmbitos sociais - comunicacional e religioso - em suas interações e afetações também de ordem técnica. A comunicação entre fiel-sagrado nos sites religiosos manifesta claramente a interposição da técnica digital nessa interação. Embora invisibilizada e "transparenciada", a técnica digital, transformada em mídia por meio de complexas operações sociossimbólicas, ganha sentido em uma análise comunicacional por ser o suporte da interação. Há, portanto, "lógicas conjuntas e pluralistas" das "pontes híbridas" entre o humano e a técnica comunicacional (PULCINI, 2006, s/p). O nosso tempo, por meio das tecnologias digitais, "torna o homem uma entidade mais conexa, e isso reforça a expressão multiforme da pessoa, quer dizer, a percepção de uma entidade múltipla e mutante: o multivíduo no lugar do indivíduo" (MARCHESINI, 2006, s/p).

É importante ressaltar, então, em primeiro lugar, que não foi simplesmente o surgimento das chamadas novas tecnologias de comunicação que desencadeou, "linear e mecanicamente" o surgimento de novas práticas sociais de produção e consumo. Segundo Verón (1997), esses novos dispositivos tecnológicos foram se inserindo em contextos de utilização múltiplos e diversificados que foram moldando, justamente, uma nova "cultura", novos processos e regularidades sociais em sua posição diante da mídia.

Como afirma Braga (2006, p. 6), a própria midiatização aparece como "processo social gerador de tecnologia", que gera uma "necessidade de tecnologia", uma "demanda apriorística por 'mais tecnologia'".

Em primeiro lugar, "o avanço tecnológico é algo socialmente determinado", defende Braga (2009, s/p). Ou seja, as tecnologias não são desenvolvidas por um inventor que está 
fora do mundo e da sociedade. São as demandas da sociedade que provocam o avanço e a inovação. "Não é a mídia, a televisão [ou a internet], que cria uma sociedade nova. É uma sociedade caracterizada por diversos eventos que precisa de processos interacionais novos, porque os atuais não conseguem dar conta do que está em efervescência. Isso determina a criação tecnológica" (BRAGA, 2009, s/p). Ou seja, há uma necessidade de algo para fazer determinada coisa, uma carência: "O homem é levado em sentido tecnopoiético a suprir uma percepção de carência, já que esta última é na realidade o resultado da parceria [ser humanotécnica]" (MARCHESINI, 2009, p. 179).

Portanto, o humano é um ser que se constrói com a alteridade (humana, animal, maquínica etc.), e a técnica (ou mesmo a própria cultura) é um instrumento de compensação do que lhe falta ou de compartilhamento do que lhe transborda. O interessante desse processo, em segundo lugar, é que a tecnologia, uma vez criada, começa a ser usada para outras coisas. Assim, "o primeiro aspecto é que a sociedade tem necessidade de viver da tecnologia. O segundo aspecto seria que é ainda a sociedade que pega uma tecnologia inventada e diz 'vamos fazer isso ou vamos fazer aquilo'. São fenômenos que não estavam implicados no próprio gesto da invenção e, portanto, não estão implicados na tecnologia" (BRAGA, 2009, s/p). Por fim, continua o autor, "a tecnologia é autopoiética; começa a se gerar a si mesma. Começa-se a inventar tecnologia por tecnologia", a partir da interacionalidade. "A força do interacional é usar a mídia para fazer coisas que não eram possíveis fazer antes. Estamos em uma fase em que somos 'aprendizes de feiticeiro'. A 'feitiçaria', que é a tecnologia, está inventada, e a sociedade aceleradamente inventa coisas" (BRAGA, 2009, s/p).

Porém, não podemos restringir nosso objeto de estudo a uma mera consequência da técnica digital, de sua informatização e códigos numéricos - nem "determinismo social”, nem “determinismo tecnológico". Ao fenômeno da digitalização, dessa forma, estão ligadas também formas e práticas de vida que são intrínsecas à internet, que nascem e se desenvolvem com ela, visto que "as atividades técnicas são formas de realização do processo de autocriação do ser humano" (RÜDIGER, 2003, p. 17). "Põe-se de manifesto nela [na técnica] um determinado tipo de humanidade", nas palavras de Donald Brinkmann (apud RÜDIGER, 2003, p. 23). Assim, o problema não é tanto o que a religião faz com a mídia, mas sim que tipo de religião está nascendo da mídia, em especial da internet, já que existem processos que distinguem, substancialmente, o espaço religioso do espaço midiático.

Portanto, cabe a análise de Gordon Graham (apud RÜDIGER, 2003), para quem as novidades tecnológicas, inclusive a internet, não são positivas apenas por serem novas, nem 
negativas apenas por serem tecnológicas. "Estamos habituados a pensar que [...] a questão da influência da tecnologia na vida do homem seja somente um problema no modo de usar" (MARCHESINI, 2009, p. 154). Segundo o autor, é justamente isso que entra em eclipse a partir do final do século XX, pois é necessário compreender que a tecnologia não é uma "escrava" a serviço do ser humano, mas ela mesma é também "teleonômica", ou seja, imprime significados, e o ser humano se modifica, e os seus predicados se transformam em várias direções. De fato, a técnica não é nem positiva, nem negativa, mas também não é neutra. "Uma técnica é produzida dentro de uma cultura, e uma sociedade encontra-se condicionada por suas técnicas. E digo condicionada, não determinada" (LÉVY, 1999, p. 25). Assim, “a alteridade não humana [...] é [...] uma entidade dialógica capaz de operar deslocamentos na dimensão humana" (MARCHESINI, 2010, p. 179).

E isso também se aplica à relação do fiel com a religião em midiatização, já que "os predicados humanos [e religiosos] são considerados qualidades emergentes pela hibridização com o não humano [ou seja, as tecnologias digitais]" (MARCHESINI, 2009, p. 158). Dessa hibridização nasce outra religião, a partir das interações entre o fiel e o sistema católico on-line. Assim, salta-se do determinismo tecnológico e social para uma perspectiva de “indeterminação inerente aos fenômenos de auto-organização" (OLIVEIRA, 2009, p. 106), incluindo também as interações entre o fiel e o sistema católico on-line. Nem a técnica determina o humano, mas nem o humano determina a técnica: é a indeterminação do devir dessa interação que merece análise, ou seja, os processos pelos quais os sujeitos se apropriam dos modos de existência através dos quais as técnicas são oferecidas.

Como indica Marchesini (2009, p. 173), podemos falar de uma "coevolução de bios e téchne [...] na definição dos predicados biológicos [e também humanos e religiosos]". Ou seja, ocorre uma construção livre, complexa, indeterminável e aberta, e não apenas um mero prolongamento, extensão ou magnificação por parte da técnica das "possibilidades já possíveis" aos seres humanos. "A linguagem, a mídia e possivelmente as novas gerações de máquinas inteligentes que imaginamos pouco acima do horizonte poderiam ser consideradas espécies companheiras que dependem de nós, mas também nos moldam poderosamente através de uma espiral coevolutiva" (LENOIR, 2009, p. 190).

É claro que a análise dos dois polos, socius e téchne, não pode ser simétrica, já que cada um deles exerce forças diferenciadas de acordo com os momentos e os locais de suas inter-relações e disputas de poder. É preciso, na verdade, fazer a "crítica da razão instrumental" e desmontar os complexos processos que se escondem por trás do mito da 
"transparência" das interfaces tecnológicas. "Por trás das técnicas, agem e reagem ideias, projetos sociais, utopias, interesses econômicos, estratégias de poder, toda a gama dos jogos dos homens em sociedade. Portanto, qualquer atribuição de um sentido único à técnica [ou às mídias] só pode ser dúbia” (LÉVY, 1999, p. 24). Ou seja, os processos sociais e os processos técnicos, invenções sociais sobre inovações tecnológicas, especialmente nas sociedades em midiatização, ocorrem em estreita relação, mas ainda há níveis claros de diferenciação entre si: "O risco de fundo [...] consiste na aceitação substancialmente acrítica da técnica [ou do social] na legitimação pura e simples de processos transformadores que, ao invés, por sua própria radicalidade, por sua mole quantitativa e por seu caráter inovador, são potencialmente portadores de patologias, seja no plano psíquico, seja no plano ético e político", defende Pulcini (2006, s/p).

Portanto, cabe ressaltar que uma hibridização e uma coevolução sociotécnicas não significam um salto qualitativo "positivo" em termos ético-político-morais. As técnicas também podem ser um saber-fazer concretizado em coisas que "constrangem, emolduram [...] as pessoas [e também a religião], cortando e impedindo a abertura e a autorrevelação, inibindo o pensamento [e também a fé]" (SANTAELLA, 2010, p. 128). Nesse sentido, retomamos a preocupação de Bento XVI (2009, n. 70) ao defender que a técnica "livra [o ser humano] das limitações físicas e alarga o seu horizonte. Mas a liberdade humana só o é propriamente quando responde à sedução da técnica com decisões que sejam fruto de responsabilidade moral" (grifo nosso).

\section{Considerações finais}

O processo de midiatização das sociedades contemporâneas encontra uma de suas manifestações nas novas práticas religiosas on-line. Essas novas modalidades de experienciação da fé são embebidas por lógicas midiáticas, em uma complexa apropriação das tecnologias comunicacionais por parte da sociedade, dando-lhes novos usos.

As mídias, assim, passam a ser meios de vivência e de prática da fé a partir de estratégias desenvolvidas pelas instituições religiosas e pelos fiéis, permeadas por modos de consciência e formas de vínculo em que a internet passa a ser uma plataforma comunicacional para a construção de novos gêneros de experiência religiosa. Aí se manifesta o papel central da técnica interposta nas interações sociais hoje, em que até mesmo o mistério do sagrado é 
revestido pela "transparência" da mídia - por meio da qual, embora mediado e midiatizado, o fiel pode compreender a sua relação com o divino como sendo "direta", sem mediações.

Assim, o problema não é tanto o que a religião $f a z$ com a mídia, mas sim que tipo de religião está nascendo da mídia, em especial da internet, por meio das microalterações da fé, marcada por essa hibridização com o não humano. Nem a técnica (internet) determina o humano (religião), mas também nem o humano determina a técnica: as inovações tecnológicas e as invenções sociais sobre essas inovações não estão dadas de antemão, e ambas retroagem umas sobre as outras. É a indeterminação do devir dessa interação que merece análise, ou seja, os processos pelos quais os sujeitos se apropriam dos modos de existência através dos quais as técnicas são oferecidas, em um desdobramento dos predicados comunicacionais e religiosos em coevolução antropotecnocomunicacional. Cabe a futuras pesquisas analisarem os desdobramentos dessas interfaces.

\section{REFERÊNCIAS}

BENTO XVI. Caritas in Veritate. Carta Encíclica sobre o Desenvolvimento Humano Integral na Caridade e na Verdade, Vaticano, 2009, s/p. Disponível em: $<$ http://migre.me/8UXxd>. Acesso em: 10 set. 2012.

BRAGA, José Luiz. Sobre "Mediatização" como Processo Interacional de Referência. Trabalho apresentado no XV Encontro Anual da Compós - Associação Nacional dos Programas de Pós-Graduação em Comunicação. Bauru, 2006.

Midiatização: a complexidade de um novo processo social. Revista IHU OnLine, São Leopoldo, ano 9, n. 289, 13 abr. 2009, s/p. Entrevista concedida a Graziela Wolfart. Disponível em: <http://migre.me/8Uxky>. Acesso em: 10 set. 2012.

. Circuitos versus Campos Sociais. In: MATTOS, Maria A.; JUNIOR, Jeder J.; JACKS, Nilda (Orgs.). Mediações e Midiatização. Salvador: EDUFBA, 2012, pp. 3152.

CABRAL, Rafael. Para Lev Manovich, Falar em "Cibercultura" é Negar a Realidade. Link. [Post]. 21 ago. 2009, s/p. Disponível em: <http://migre.me/8MbHz>. Acesso em: 10 set. 2010.

ESPOSITO, Roberto. A Natureza Humana Depois do Humanismo. In: FELICE, Massimo Di; PIREDDU, Mario. Pós-Humanismo: As Relações entre o Humano e a Técnica na Época das Redes. São Caetano do Sul: Difusão Editora, 2010.

FAUSTO NETO, Antônio. Midiatização, Prática Social - Prática de Sentido.

Trabalho apresentado no Seminário sobre Midiatização, Rede Prosul. São Leopoldo, 2005. 
. Olhares sobre a recepção através das bordas da circulação. Trabalho apresentado no XVIII Encontro Anual da Compós - Associação Nacional dos Programas de Pós-Graduação em Comunicação. Belo Horizonte, 2009.

FELICE, Massimo Di; PIREDDU, Mario. Pós-Humanismo: As Relações entre o Humano e a Técnica na Época das Redes. São Caetano do Sul: Difusão Editora, 2010.

FELINTO, Erick. Passeando no Labirinto: Ensaios sobre as Tecnologias e as Materialidades da Comunicação. Porto Alegre: EDIPUCRS, 2006.

"Sem Mapas para esses Territórios": A Cibercultura como Campo de Conhecimento. Trabalho apresentado no XXX Congresso Brasileiro de Ciências da Comunicação, Santos, 2007.

GOMES, Pedro Gilberto. O Processo de Midiatização da Sociedade e sua Incidência em Determinadas Práticas Sociossimbólicas na Contemporaneidade: A Relação Mídia e Religião. In: FAUSTO NETO, Antônio et al. (Orgs). Midiatização e Processos Sociais na América Latina. São Paulo: Paulus, 2008.

. Fenomenologia da Comunicação. In: FERREIRA, Jairo; PAOLIELLO, Francisco J.; SIGNATES, Luiz A. Estudos da Comunicação: Transversalidades Epistemológicas. São Leopoldo: Unisinos, 2010.

KROTZ, Friedrich. The Meta-Process of 'Mediatization' as a Conceptual Frame. Global Media and Communication, Thousand Oaks, v. 3, 2007, p. 256-260. Disponível em: <http://migre.me/4Cvan>. Acesso em: 10 set. 2012.

LENOIR, Timothy. Biotécnica, Nootécnica e Nanotécnica: Desafios para as Ciências Humanas. In: NEUTZLING, Inácio; ANDRADE, Paulo Fernando Carneiro de (Orgs.). Uma Sociedade Pós-Humana: Possibilidades e Limites das Nanotecnologias. São Leopoldo: Unisinos, 2009.

LÉVY, Pierre. Cibercultura. São Paulo: Ed. 34, 1999, p. 25.

MARCHESINI, Roberto. O pós-humanismo como ato de amor e hospitalidade. Revista IHU On-Line, São Leopoldo, ano 6, n. 200, 16 out. 2006. Disponível em: $<$ http://migre.me/8UzBA $>$. Acesso em: 10 set. 2012.

. Uma Hermenêutica para a Tecnociência. In: NEUTZLING, Inácio; ANDRADE, Paulo Fernando Carneiro de (Orgs.). Uma Sociedade Pós-Humana: Possibilidades e Limites das Nanotecnologias. São Leopoldo: Unisinos, 2009.

Contra a Pureza Existencialista, Rumo a Novos Modelos de Existência. In: FELICE, Massimo Di; PIREDDU, Mario. Pós-Humanismo: As Relações entre o Humano e a Técnica na Época das Redes. São Caetano do Sul: Difusão Editora, 2010.

MATA, Maria Cristina. De la Cultura Masiva a la Cultura Mediatica. Dialogos de la Comunicación, Lima, n. 56, out. 1999. 
MIÈGE, Bernard. A Sociedade Tecida pela Comunicação: Técnicas da Informação e da Comunicação entre Inovação e Enraizamento Social. São Paulo: Paulus, 2009.

OLIVEIRA, Luiz Alberto. Cibercentauros: Sobre a Possível Hibridização entre Homens e Máquinas. In: NEUTZLING, Inácio; ANDRADE, Paulo Fernando Carneiro de (Orgs.). Uma Sociedade Pós-Humana: Possibilidades e Limites das Nanotecnologias. São Leopoldo: Unisinos, 2009.

PIREDDU, Mario. A Carne do Futuro: Utopia da Desmaterialização. In: FELICE, Massimo Di; PIREDDU, Mario. Pós-Humanismo: As Relações entre o Humano e a Técnica na Época das Redes. São Caetano do Sul: Difusão Editora, 2010.

PULCINI, Elena. Um poder sem controles. Revista IHU On-Line, São Leopoldo, ano 6, n. 200, 16 out. 2006. Disponível em: <http://migre.me/8Uzlx>. Acesso em: 10 set. 2012.

RÜDIGER, Francisco. Introdução às Teorias da Cibercultura: Perspectivas do Pensamento Tecnológico Contemporâneo. Porto Alegre: Sulina, 2003.

SANTAELLA, Lucia. Pós-humano, pós-humanismo e anti-humanismo: discriminações. In: FELICE, Massimo Di; PIREDDU, Mario. Pós-Humanismo: As Relações entre o Humano e a Técnica na Época das Redes. São Caetano do Sul: Difusão Editora, 2010.

SBARDELOTTO, Moisés. Interações em Rituais Católicos: Uma Análise da Prática Religiosa em Tempos De Internet. In: RIBEIRO, José C.; FALCÃO, Thiago; SILVA, Tarcízio. Mídias Sociais: Saberes e Representações. Salvador: EDUFBA, 2012a, pp. 131-152.

Deus em bits e pixels: Um estudo sobre interface em sites católicos. Ciberlegenda, Rio de Janeiro: UFF, v. 1, n. 26, pp. 123-135, 2012b. Disponível em: $<$ http://migre.me/apooQ>. Acesso em: 10 set. 2012.

"E o Verbo se fez bit": Uma análise da experiência religiosa na internet. Cadernos IHU. São Leopoldo: Instituto Humanitas Unisinos, ano 9, n. 35, 2011. Disponível em: $<$ http://goo.gl/wUvK1>. Acesso em: 10 set. 2012.

SCOLARI, Carlos. Hacer Clic: Hacia una Sociosemiótica de las Interacciones Digitales. Barcelona: Gedisa, 2004.

Hipermediaciones: Elementos para una Teoría de la Comunicação Digital Interactiva. Barcelona: Gedisa, 2008.

VERÓN, Eliséo. Esquema para el Analisis de la Mediatización. Diálogos de la Comunicación. Lima, n. 48, out. 1997. 